\title{
Value for Correction: Documenting Perceptions about Peer Correction of Misinformation on Social Media in the Context of COVID-19
}

\author{
LETICIA BODE \\ Georgetown University, United States \\ EMILY K. VRAGA \\ University of Minnesota, United States
}

\begin{abstract}
Although correction is often suggested as a tool against misinformation, and empirical research suggests it can be an effective one, we know little about how people perceive the act of correcting people on social media. This study measures such perceptions in the context of the onset of the COVID-19 pandemic in 2020, introducing the concept of value for correction. We find that value for correction on social media is relatively strong and widespread, with no differences by partisanship or gender. Neither those who engage in correction themselves nor those witnessing the correction of others have higher value for correction. Witnessing correction, on the other hand, is associated with lower concerns about negative consequences of correction, whereas engaging in correction is not.
\end{abstract}

Keywords: social media, misinformation, correction

Leticia Bode: 1b871@georgetown.edu Date submitted: 2020-12-17

Copyright (C) 2021 (Leticia Bode, Emily K. Vraga). Licensed under the Creative Commons AttributionNonCommercial-NoDerivatives 4.0 International Public License. Available at: http://journalqd.org 
Although scholars continue to debate and test interventions aimed at combatting health misinformation, one approach that has gained some traction is correcting misinformation on social media. Research consistently shows that correcting health misinformation on social media - which we define as "the presentation of information designed to rebut an inaccurate claim or a misperception" (Vraga \& Bode, 2020, p. S278) - successfully reduces misperceptions (Walter, Brooks, Saucier, \& Suresh, 2020). This approach is particularly promising because it affects not only those who experience the correction directly, but also those who witness it, sometimes referred to as observational correction (Vraga \& Bode, 2020).

This is useful from an academic perspective - we know that in an experimental setting, people respond well to witnessing correction. However, this may not translate into how such activities are received by people who see them or experience them firsthand. This is important to explore, because if people value correction, they may be more likely to accept a correction or more willing to correct others. On the other hand, if they think correction is inappropriate to engage in on social media, or likely to end badly for the person doing the correction, they may be likely less willing to engage in such behaviors themselves. For observational correction to work effectively, it needs to scale - lots of social media users need to regularly engage in correcting one another (Bode, 2020). Therefore, it is important to determine whether there is a norm of correction as a positive or normatively good thing. That is the goal of this manuscript - to document how people perceive correction of misinformation on social media.

\section{Literature Review}

Broadly speaking, research strongly suggests that correction is effective at reducing misperceptions, both on social media (Walter et al., 2020) and in other contexts (Wood \& Porter, 2019). Additionally, although we have evidence that at least a sizeable minority of social media users correct others when they see misinformation being shared (Bode \& Vraga, 2021; Chadwick \& Vaccari, 2019; Tandoc, Lim, \& Ling, 2020), little is known 
about attitudes towards correction on social media. Political debate and conflict on social media are generally disliked (Thorson, 2014; Vraga et al., 2015), which may translate into a similar negative attitude towards engaging in correction. Supporting this argument, previous research suggests that many users avoid correcting others because they believe it will create conflict (Tandoc et al., 2020), and in some contexts, "correction is viewed as transgressive or threatening" (Malhotra, 2020, p. 2).

Although value for correction has not directly been measured, research has considered attitudes toward fact checking organizations more broadly. In general, across a study of six different nations, people reported being favorable towards "the fact checking movement in journalism," and also said they wanted more fact checks (Lyons, Merola, Reifler, \& Stoeckl, 2020, p. 477). However, this is not to say that these attitudes towards organizational fact checking will be reflected in everyday user's attitudes towards "correction" more broadly.

Related literature has also considered who shares fact checks - a particular type of peer correction - on social media (Amazeen, Vargo, \& Hopp, 2018; Margolin, Hannak, \& Weber, 2018; Shin \& Thorson, 2017). This research suggests that people who are older, more liberal, and moderate (as compared to high or low) in Need For Orientation are most likely to post fact checks (Amazeen, et al., 2018). When people do share fact checks on social media, they tend to be congruent with their political beliefs (Amazeen, et al., 2018; Shin \& Thorson, 2017), although other research suggests many people mention fact checking organizations in order to criticize them (Brandtzaeg \& Folstad, 2017). At least one study suggests that people who are the target of a fact check from another user may accept that fact check, especially when the fact check comes from a friend (Margolin et al., 2018) - which may provide further evidence for both the acceptability and the effectiveness of fact checks on social media.

Sharing a fact check might be construed as an endorsement of correction, though it misses the portion of the population who values correction but does not necessarily engage 
in it (or does so without sharing a fact check). Most people - 89\% according to one study (Amazeen, et al., 2018) - do not share fact checks on social media, so for a substantial portion of the population we do not have a clear understanding of their value for correction.

We think that this idea of value for correction should guide willingness to engage in correcting others on social media, given long-standing research suggesting that norms and attitudes tend to drive behaviors (Ajzen, 1985; Kim, Lee, \& Yoon, 2015), but research has yet to determine to what extent people are comfortable with others engaging in correction on social media. The first goal of this manuscript is therefore to determine to what extent people value correction of misinformation on social media platforms (RQ1).

Second, we contribute to the literature by offering concrete measures of value for correction. We therefore document the extent to which different ways of measuring value for correction align, using an exploratory factor analysis. We include both positive elements - (1) I like it when people correct others on social media, (2) People should respond when they see someone sharing misinformation on social media, and (3) Addressing misinformation on social media is everyone's responsibility - and negative elements - (4) Responding to misinformation on social media just confuses everyone, and (5) When people respond to misinformation on social media, they just encourage trolling - to ensure that we are capturing a range of attitudes towards correction.

We think of these as two separate concepts. The first group of elements we refer to as value for correction. The last two elements, reflecting possible negative effects of correction, we refer to as correction concerns. Because, as far as we know, we are the first to measure these concepts, we ask how these five measures go together using an exploratory factor analysis to examine whether two separate concepts emerge, whether all five elements factor together, or whether each represents a unique opinion about correction on social media (RQ2). If two concepts do emerge, we will further examine whether value for correction and correction concerns relate to one another if at all (RQ3). 
There is some reason to believe that perceptions about correction might not be evenly distributed across the population. For example, research has shown a significant gap between endorsing social media platforms fact checking politicians $-87 \%$ of Democrats approve of it, whereas only 57\% of Republicans do (Rich, Milden, \& Wagner, 2020). And there are demographic differences in who shares fact checks as noted above (Amazeen, et al., 2018). If some subgroups of the population value correction more than others, that might mean that some subpopulations are less self-correcting, and are therefore more vulnerable to misinformation. To determine if this is the case, we further examine whether beliefs about the value and risks of correction differ depending on a range of demographic characteristics, including partisanship, gender, and age (RQ4).

Finally, there is reason to believe that personal experience with misinformation and correction on social media might inform opinions about it. People that see more misinformation, for instance, might think correction is more valuable. Seeing someone else be corrected, on the other hand, could lead you to think correction is valuable for society, or alternatively that it is a risky endeavor. We therefore explore whether and how experiences with misinformation and correction - seeing misinformation, seeing correction, or engaging in correction - are related to value for correction and to correction concerns (RQ5).

\section{Methods}

\section{Sample}

Data for this analysis come from a survey conducted using an online sample March 27th-28th, 2020. The sample $(\mathrm{N}=1094)$ was recruited using Lucid Theorem, an online sample provider which partners with other companies that recruit participants through "emails, push notifications, in-app pop-ups, and similar approaches" (Lucid, 2020). Samples are intended to mirror the U.S. population in terms of age, race, ethnicity, party affiliation, education, income, and region (Coppock \& McClellan, 2019). 
Our sample is $51 \%$ male, $76 \%$ white, with an average age of 45 . There are more Democrats (46\%) than Republicans (36\%) or Independents (19\%), and 39\% of participants had at least a Bachelor's degree (see Table 1a and Table $1 \mathrm{~b}$ for sample descriptive statistics).

\section{Data Preparation}

Data is weighted to Census values (for gender, race, and education), Gallup data (for partisanship), and the General Social Survey (for age) using raking weights. For all analyses below, we limit the sample to those participants who report using at least one social media platform at least "regularly" $(\mathrm{N}=1043)$, in order to capture the opinions of those who are sufficiently familiar with social media to have well-formed opinions about correction in those spaces.

\section{Measures}

In the questionnaire, respondents first answered questions about their experiences with misinformation and correction, then answered questions about attitudes towards correction, and answered demographic questions last.

Attitudes towards correction: Participants rated five statements (presented in a random order) reflecting attitudes about correction on seven-point scales from "strongly disagree" to "strongly agree:" (1) I like it when people correct others on social media, (2) People should respond when they see someone sharing misinformation on social media, (3) Addressing misinformation on social media is everyone's responsibility, (4) Responding to misinformation on social media just confuses everyone, and (5) When people respond to misinformation on social media, they just encourage trolling. These are taken from a read of the relevant literature on why people do or do not correct others (e.g. 
Tandoc, et al., 2020 - see especially Figure 1), and who they think is responsible for addressing misinformation (e.g., Mitchell, et al., 2019).

Demographics: In order to determine how attitudes about correction are distributed in the population, we measure relevant demographics, including age (measured with a single open-ended question asking people to respond to the question "what is your age"), gender (a single question asking "what is your gender" and offering male, female, and other/non-binary as categories; four people responded as other/non-binary and were dropped from the analysis as no weighting was possible for this group), education (measured on a six-point scale from "did not complete high school" to "graduate degree"; for analysis this was collapsed into three categories: high school degree or less, some college or associates degree, and college or graduate degree) and income (median income $=\$ 50,000-\$ 74,999$; measured as total household income on a five-point scale from "less than $\$ 25,000$ " to " $\$ 100,000$ or more"; for analysis this was collapsed into less than $\$ 50,000$ or more than $\$ 50,000)$. Party affiliation, measured on a seven-point scale from Strong Democrat (1) to Strong Republican (7), and partisan strength (a folded measure of the party affiliation scale, measured 1 to 4 , where 4 is the strongest partisanship) are also included. Descriptive statistics are included in Table 1a and Table $1 \mathrm{~b}$.

Table 1a. Descriptive statistics of the sample

\begin{tabular}{ll}
\hline Variable & Mean (SD) \\
\hline Age & $47.57(17.01)$ \\
Partisanship (R. high) & $3.90(2.14)$ \\
Partisan strength & $1.90(0.97)$ \\
\hline
\end{tabular}


Table 1b. Descriptive statistics of the sample

\begin{tabular}{ll}
\hline Variable & Percent \\
\hline Female & $48.7 \%$ \\
High school degree or less & $24.4 \%$ \\
Some college or associates & $43.8 \%$ \\
College or graduate degree & $31.8 \%$ \\
Income $<\$ 50,000$ & $50.6 \%$ \\
Income $\geq \$ 50,000$ & $49.4 \%$ \\
\hline
\end{tabular}

Experience with Misinformation and Correction: To measure different experiences with correction on social media with regard to COVID-19, participants were asked, "In the past week on social media, with regards to COVID-19, do you recall:" (1) Seeing SOMEONE ELSE SHARING misinformation, (2) Seeing SOMEONE ELSE being told that something they shared was misinformation, and (3) TOLD someone they were sharing misinformation. $56.6 \%$ of our participants reported having seen someone sharing misinformation about COVID-19 in the past week; among those who saw misinformation, $51.3 \%$ reported having witnessed correction and $35.1 \%$ reported having corrected someone they saw sharing misinformation.

\section{Results}

Descriptively we find that there is broad support for peer correction on social media (RQ1, see Figure 1). Majorities of participants report they like it when people correct others on social media $(56.9 \%)$, and even more believe it is normative $(68.9 \%)$ or the public's responsibility $(67.5 \%)$. However, that does not mean people are unaware of the risks; roughly half of participants believe corrections can cause confusion (47.2\%) or encourage trolling (52.5\%). 


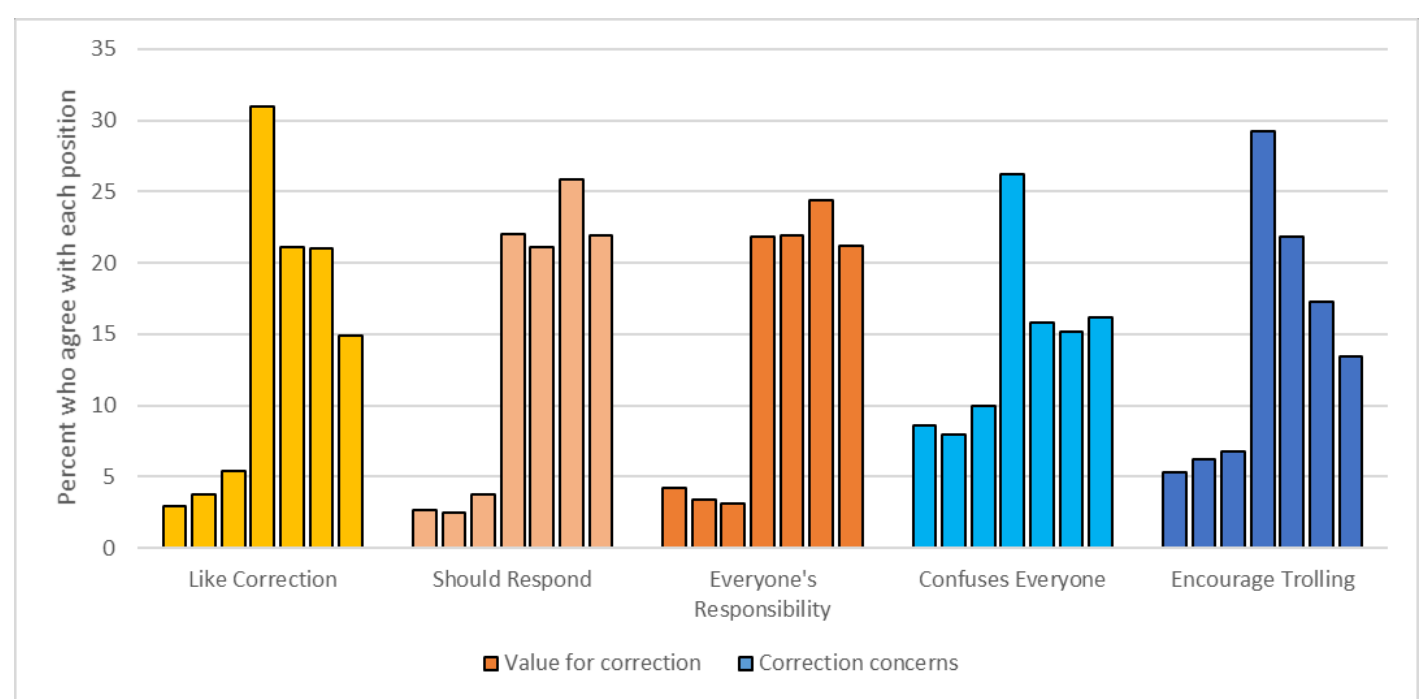

Figure 1: Perceptions of correction

Note: Bars are arranged left to right from strongly disagree to strongly agree.

Next, we tested how these indicators align (RQ2). An exploratory factor analysis using a promax rotation reveals two factors: one for value for correction $35.7 \%$ of variance, $\alpha=.79, M=5.06, S . D .=1.26$, orange bars in Figure 1) and one for correction concern $(16.7 \%$ of variance, $r=.46, p<.001, M=4.53$, S.D. $=1.46$, blue bars in Figure 1$)$. These two concepts are modestly positively correlated ( $r=.14, p<.001, \mathrm{RQ} 3)$, suggesting that those who have higher value for correction are also more concerned about how it might affect people. Results from the factor analysis are presented in Table 2. 
Table 2. Factor Analysis of Perceptions of Social Media Content

\begin{tabular}{|c|c|c|c|c|c|}
\hline Variable & $\begin{array}{l}\text { Factor 1: } \\
\text { Value for } \\
\text { Correction }\end{array}$ & $\begin{array}{l}\text { Factor 2: } \\
\text { Correction } \\
\text { concerns }\end{array}$ & Mean & SD & $\begin{array}{l}\text { Percent who } \\
\text { somewhat } \\
\text { agree }\end{array}$ \\
\hline $\begin{array}{l}\text { I like it when people correct } \\
\text { others on social media }\end{array}$ & .65 & .03 & 4.86 & 1.46 & $56.9 \%$ \\
\hline $\begin{array}{l}\text { People should respond when } \\
\text { they see someone sharing } \\
\text { misinformation on social } \\
\text { media }\end{array}$ & .82 & -.02 & 5.21 & 1.46 & $68.9 \%$ \\
\hline $\begin{array}{l}\text { Addressing misinformation } \\
\text { on social media is } \\
\text { everyone's responsibility }\end{array}$ & .78 & -.01 & 5.12 & 1.55 & $67.5 \%$ \\
\hline $\begin{array}{l}\text { Responding to } \\
\text { misinformation on social } \\
\text { media just confuses } \\
\text { everyone }\end{array}$ & -.04 & .67 & 4.43 & 1.80 & $47.2 \%$ \\
\hline $\begin{array}{l}\text { When people respond to } \\
\text { misinformation on social } \\
\text { media, they just encourage } \\
\text { trolling }\end{array}$ & .05 & .67 & 4.61 & 1.59 & $52.5 \%$ \\
\hline
\end{tabular}

\begin{tabular}{lll}
\hline Variance Explained & $35.70 \%$ & $16.68 \%$ \\
\hline Reliability & $\alpha=.79$ & $r=.45$ \\
\hline Scale Mean & 5.06 & 4.52 \\
\hline Scale $S D$ & 1.25 & 1.44 \\
\hline
\end{tabular}

Note: Exploratory factor analysis using principle axis factoring and a promax rotation for perceptions of social media correction. 
We further examine how these perceptions are distributed among the population (RQ4; Table 3, Figure 2), using Ordinary Least Squares regression predicting each of the two variables - value for correction and correction concerns - created from the factor analysis described above. We find that older adults (purple bars in Figure 2) are both more supportive of the value of correction overall and warier about its risks. Importantly, however, we observe no partisan differences in attitudes, suggesting social media correction is valued across the political spectrum (blue bars in Figure 2). Likewise, there are no gender (green bars in Figure 2) or educational differences (orange bars in Figure 2) in our sample. However, these models explain very little variance - and the model predicting correction concerns is not significant overall, therefore any results (or lack thereof) must be interpreted with extreme caution.

Table 3. Predicting Value for Correction and Correction Concerns

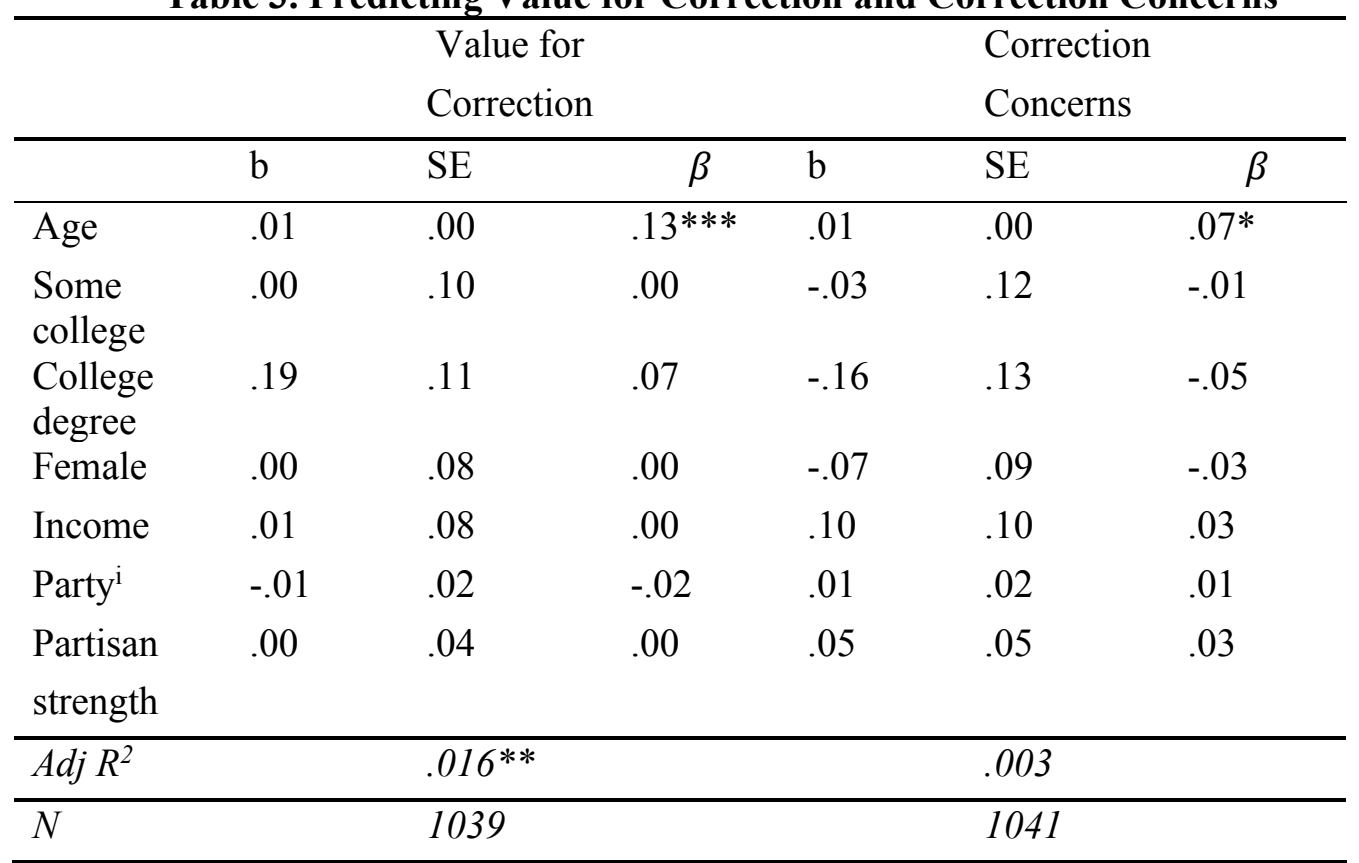

Note: Ordinary least squares regression, Standardized beta coefficients reported. $+\mathrm{p}<.10$, ${ }^{*} \mathrm{p}<.05, * * \mathrm{p}<.01, * * * \mathrm{p}<.001$

${ }^{i}$ Party is measured on a seven-point scale, with higher values reflecting more Republican responses. 


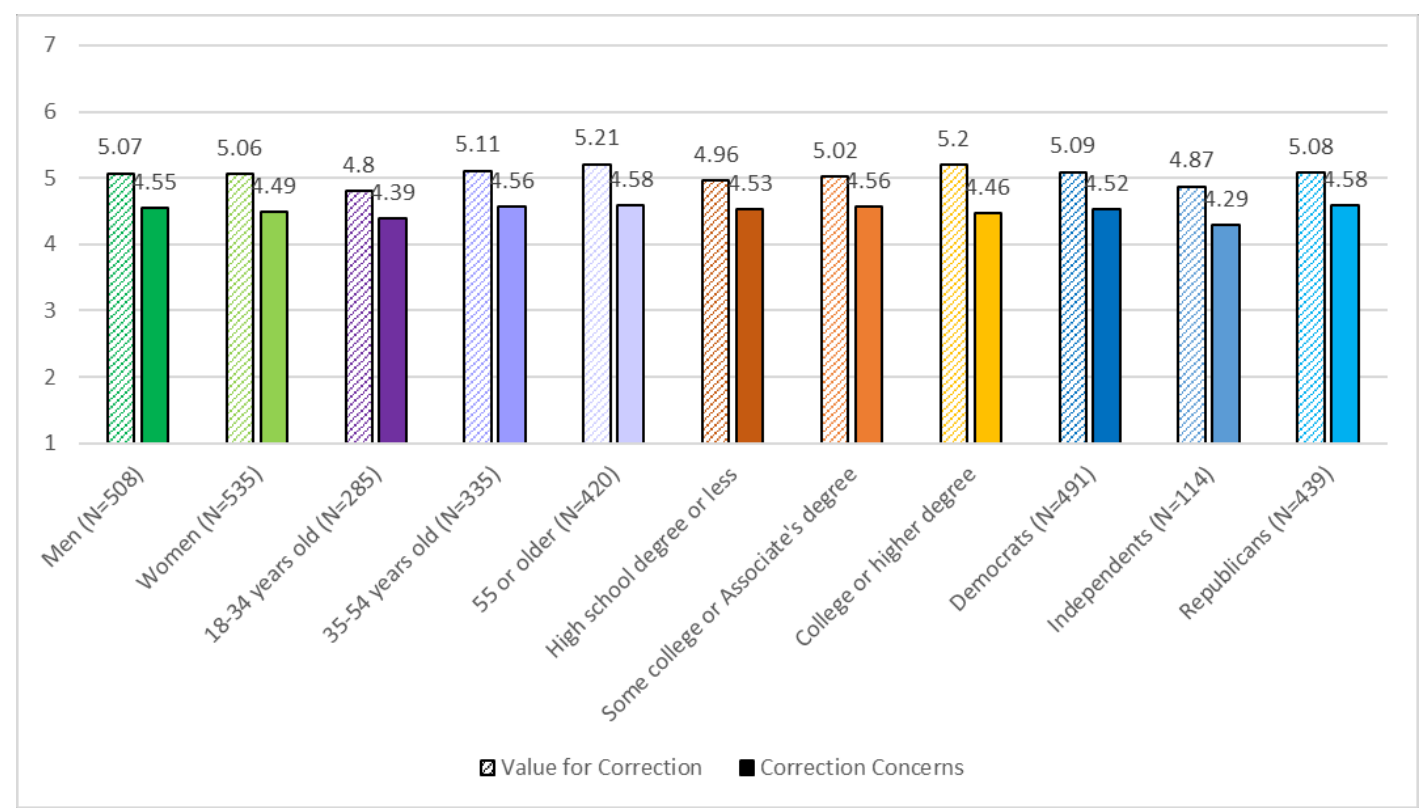

Figure 2: Value for Correction and Correction Concerns by Subgroup

Note: Green bars represent gender, purple bars represent age, orange bars represent education, and blue bars represent partisanship. Age is the only variable where we see a modest but significant difference in attitudes.

Finally, connecting experiences and behaviors (RQ5), we consider the effects of exposure to misinformation and correction on social media with attitudes towards social media correction. Among our full sample, no relationship emerges between exposure to misinformation on social media and either value for correction or correction concerns (Table 4). To examine the effects of exposure to correction, we limit our analyses to those $56.6 \%$ of participants who reported seeing misinformation on social media in the past week, as their experiences with correction are most relevant to our research questions (that is, you cannot have experience with correction if you have not witnessed misinformation in need of correction; $N=584-587$; Table 5). In this subsample, too, we find no evidence of a relationship between experiences with correction and value for correction. However, it is worth noting that this model explains relatively little variance in value for corrections (about 3.0\%), suggesting much more work is necessary. 
Table 4. Misinformation Experience and its Relationship with Value for Correction and Correction Concerns

\begin{tabular}{lllllll}
\hline & \multicolumn{3}{c}{$\begin{array}{l}\text { Value for } \\
\text { Correction }\end{array}$} & \multicolumn{3}{c}{$\begin{array}{l}\text { Correction } \\
\text { Concerns }\end{array}$} \\
\hline & $\mathrm{b}$ & $\mathrm{SE}$ & \multicolumn{1}{c}{$\beta$} & $\mathrm{b}$ & $\mathrm{SE}$ & $\beta$ \\
\hline Age & .01 & .00 & $.14^{* * *}$ & .01 & .00 & $.08^{*}$ \\
Some college & -.01 & .10 & -.01 & -.04 & .12 & -.01 \\
College degree & .17 & .11 & .06 & -.18 & .13 & -.06 \\
Female & -.00 & .08 & -.00 & -.08 & .09 & -.03 \\
Income & .00 & .08 & .00 & .09 & .10 & .03 \\
Party & -.01 & .02 & -.02 & .01 & .02 & .01 \\
Partisan & .00 & .04 & .00 & .05 & .05 & .03 \\
strength & .10 & .08 & .04 & .03 & .09 & .01 \\
See & & & & & & .003 \\
Misinformation & & $.017^{* *}$ & & & 1038 \\
\hline Adj $R^{2}$ & & 1035 & & & \\
\hline$N$ &
\end{tabular}

Note: Ordinary least squares regression, Standardized beta coefficients reported. $+\mathrm{p}<.10$, ${ }^{*} \mathrm{p}<.05,{ }^{* *} \mathrm{p}<.01,{ }^{* * *} \mathrm{p}<.001$

${ }^{i}$ Party is measured on a seven-point scale, with higher values reflecting more Republican responses.

Turning to concerns about correction, we observe a different pattern of results. Here, witnessing correction on social media is associated with lower perceptions that such corrections carry negative outcomes, while the act of correcting others is not associated with this attitude (Table 5). However, like the model showing the value of correction, the model presenting correction concern explains relatively little variance overall (about $1.5 \%$ ), so there is much we still do not know about who is concerned about correction outcomes. 
Table 5. Correction Experience and its Relationship with Value for Correction and Correction Concerns

\begin{tabular}{lllllll}
\hline \multicolumn{7}{c}{ Among those who see misinformation } \\
\hline & $\begin{array}{c}\text { Value for } \\
\text { Correction }\end{array}$ & & \multicolumn{3}{l}{ Correction } \\
Concerns
\end{tabular}

Note: Ordinary least squares regression, Standardized beta coefficients reported. $+\mathrm{p}<.10$, ${ }^{*} \mathrm{p}<.05,{ }^{* *} \mathrm{p}<.01,{ }^{* * *} \mathrm{p}<.001$

${ }^{i}$ Party is measured on a seven-point scale, with higher values reflecting more Republican responses.

\section{Discussion}

People broadly endorsed the value of online corrections, even as they also acknowledge their downsides. Majorities of Americans report not only liking correction on social media, but seeing it as a public responsibility. Seeing correction, at least with regards to COVID-19, is also relatively common- of the nearly $60 \%$ of our participants who saw misinformation about COVID-19 being spread on social media in the past week, over half also saw correction occurring. Therefore, both injunctive (you should correct) and descriptive (people do correct) norms may be emerging that support observational correction (Ajzen, 1985; Cialdini et al., 2006). 
However, people are not endorsing correction on social media blindly, but also recognize that it can carry some negative potential consequences. Value for correction on social media tends to be associated with greater recognition of those risks. In other words, support for correction on social media endures in spite of this acknowledgement of risk. Future research should explore whether reducing perceptions of the risks of correction enhances value for correction, as this may represent an important strategy for bolstering these normative beliefs.

Importantly, these attitudes towards correction are broadly shared across the population, with a few notable exceptions. Older adults are both more likely to endorse the value of correction, as well as express more concerns about its drawbacks. Research is mixed as to whether older adults are more (e.g., Guess et al., 2019) or less susceptible to misinformation (Baum et al., 2020; Roozenbeek, et al., 2020), and these different findings may be context-dependent. In either case, older adults' experiences with misinformation and correction may lead them to be more familiar with both the benefits and costs associated with correction.

Gender is not associated with perceptions of the value for correction or its downsides on social media, though it is worth noting that marginalized groups - notably women and people of color - are more likely to be harassed online (Hess, 2014), and may be at greater risk of negative outcomes if engaging in correction, even if these groups do not perceive it as a riskier endeavor according to our data.

Of additional note is the lack of relationship between political orientations and attitudes towards correction. Especially in the context of COVID-19, emerging partisan divides in the United States in terms of perceptions of disease severity, exposure to misinformation, and preventative behaviors have complicated public health efforts (Allcott et al., 2020; Gollwitzer et al., 2020; Schaeffer, 2020). If perceptions of the value of correction are not systematically biased, it may represent an opportunity to reach a 
receptive audience across partisan differences. However, these measures ask about acceptance of correction theoretically. People's attitudes towards correction may differ depending on their concrete experiences with correction. In other words, people may say they support and value correction in the abstract, but when faced with corrective material - especially when it goes against their beliefs and particularly when they are the ones being corrected - still respond negatively.

Our data provide little evidence that indirect experiences with misinformation and correction are related to value for correction. People who report seeing misinformation were neither more nor less likely to approve of correction on social media, nor were they more or less aware of the risks. Witnessing correction by someone else on social media was also unassociated with value for correction. This is somewhat surprising, and seems to contradict the idea that descriptive norms (that is, seeing people correct one another) affect injunctive norms (that is, value for correction).

Witnessing correction is, however, associated with lower concerns about correction. If people see correction take place and the corrector emerge unscathed, they may translate that into lower concerns about the negative consequences of engaging in correction. It would be helpful to know more about the details of how people witness correction, and in particular their perception of how the correction is received. Future research might employ more detailed survey or interview questions to explore the relationship between witnessing correction and concerns about it further.

Direct experiences with correction - in this case, reporting that you have corrected others on social media - is not associated with either value for correction or with correction concerns. Although we might have expected those engaging in correction to value it more, this suggests that value for correction extends beyond just the relatively small percentage of people who are correcting others. Even people who do not have the time, inclination, or ability to correct others still find it valuable. 
This study has several limitations. First, we rely on self-reports of experience with both misinformation and correction. Such reports are likely subject to recall error (Sudman, Bradburn, \& Schwarz, 1996), and may be either under- or over-reported (Allcott \& Gentzkow, 2017; Guess, 2015; Jurgens, Stark, \& Magin, 2019). Future research could pair attitudes about correction with digital trace data to gain a better sense of these relationships.

While our sample approximates a national population, we employed a nonprobability opt-in online sample. Perhaps because it is from an online sample, the vast majority of our sample $-95 \%$ - is a regular user of social media. While we think this is the most relevant group of people to query about their thoughts on the value of social media correction, it also suggests our sample is somewhat atypical, and less frequent users may have different opinions on the matter. Future research should continue to explore these questions using representative samples, and test whether attitudes towards correction differ across countries, cultures, or contexts (Malhotra, 2020; Vraga, Bode, \& Tully, 2020). Related, because we had limited numbers of most racial categories, we were not able to examine the impact of race on attitudes about correction on social media. As research shows that people of different races use social media differently (e.g. Clark, 2014), this is an important element to consider.

It is also noteworthy that we ask about attitudes towards correction within a specific context - with regards to COVID-19 misinformation in April of 2020, when concern about COVID-19 was quite high (57\% reported being "very" or "somewhat" concerned; Gallup, 2020). Even though the questions measuring value for correction and correction concerns did not mention COVID-19 explicitly, they followed other questions on the topic, and it was a highly salient issue at the time of the survey. It seems possible - or even likely - that norms and attitudes about correction will differ depending on the context in which they are examined. For example, people may endorse correction for a public health crisis during an infectious disease event, but think it inappropriate when it comes to political misinformation (Rich, et al., 2020). Norms also likely vary from platform to platform (Waterloo, et al., 2018), so examining how attitudes about correction differ depending on 
what social media people use would also be interesting to consider. Future research should do more to examine attitudes towards correction within multiple issue contexts, and examine the extent to which correction value is static over time, as well as what can increase or decrease correction value or concerns.

Finally, our models explain relatively little variance in correction attitudes, suggesting there is much about people's attitudes (and more broadly, about their experiences with correction) that we do not yet know. Future research should investigate what attitudes, characteristics, experiences, and behaviors affect opinions about correction on social media. Anything that is likely to affect perceptions of norms of such behavior including more nuanced measures of experience with correction, such as whether someone witnessed a correction that was then accepted, or alternatively whether they witnessed someone being criticized for engaging in correction - may be particularly impactful.

Clearly this is only a preliminary effort in better understanding how people value peer-to-peer correction of social media users, and much more work needs to be done to understand how these perceptions develop, what affects them, and how much they change over time. This study provides initial evidence that the American public broadly values correction on social media, while still being aware of its downsides. Such norms provide an important foundation that campaigns designed to promote correction can build upon, encouraging more and better correction by social media users.

\section{References}

Ajzen, I. (1985). From intentions to actions: A theory of planned behavior. In Action control (pp. 11-39). Springer, Berlin, Heidelberg.

Allcott, H., Boxell, L., Conway, J., Gentzkow, M., Thaler, M., \& Yang, D. Y. (2020). Polarization and public health: Partisan differences in social distancing during the Coronavirus pandemic. NBER Working Paper, (w26946). https://papers.ssrn.com/sol3/papers.cfm?abstract_id=3574415

Allcott, H., \& Gentzkow, M. (2017). Social media and fake news in the 2016 election. Journal of economic perspectives, 31(2), 211-36. 
https://www.aeaweb.org/articles?id=10.1257/jep.31.2.211

Amazeen, M. A., Vargo, C. J., \& Hopp, T. (2019). Reinforcing attitudes in a gatewatching news era: Individual-level antecedents to sharing fact-checks on social media. Communication Monographs, 86(1), 112-132. https://www.tandfonline.com/doi/abs/10.1080/03637751.2018.1521984?journalC ode $=$ rcmm 20

Baum, M., Ognyanova, K., Chwe, H., Quintana, A., Perlis, R.H., Lazer, D., Druckman, J., Santillana, M., Lin, J., Volpe, J.D., Simonson, M., \& Green, J. (2020). The state of the nation: A 50-state Covid-19 survey report \#14: Misinformation and vaccination acceptance. Retrieved from: https://covidstates.org/

Bode, L. (2020). User Correction as a Tool in the Battle Against Social Media Misinformation.Georgetown Law and Technology Review, 4(2), 367-378. https://georgetownlawtechreview.org/user-correction-as-a-tool-in-the-battleagainst-social-media-misinformation/GLTR-07-2020/

Bode, L., \& Vraga, E.K. (Forthcoming). "Correction Experiences on Social Media during COVID-19." Social Media + Society.

Brandtzaeg, P. B., \& Følstad, A. (2017). Trust and distrust in online fact-checking services. Communications of the ACM, 60(9), 65-71. https://dl.acm.org/doi/10.1145/3122803

Chadwick, A., \& Vaccari, C. (2019). News sharing on UK social media: Misinformation, disinformation, and correction. Loughborough University. Retrieved from: https://repository.lboro.ac.uk/articles/News_sharing_on_UK_social_media_misinf ormation_disinformation_and_correction/9471269/1

Cialdini, R. B., Demaine, L. J., Sagarin, B. J., Barrett, D. W., Rhoads, K., \& Winter, P. L. (2006). Managing social norms for persuasive impact. Social influence, 1(1), 315. https://www.tandfonline.com/doi/abs/10.1080/15534510500181459

Clark, M. (2014). To tweet our own cause: A mixed-methods study of the online phenomenon "Black Twitter". https://cdr.lib.unc.edu/concern/dissertations/gt54kn18h

Coppock, A., \& McClellan, O. A. (2019). Validating the demographic, political, psychological, and experimental results obtained from a new source of online survey respondents. Research \& Politics, 6(1), 1-14. https://journals.sagepub.com/doi/full/10.1177/2053168018822174 
Gallup. (2020). Oct. 19, 2020. Retrieved from: https://news.gallup.com/opinion/gallup/308126/roundup-gallup-covidcoverage.aspx

Gollwitzer, A., Martel, C., Brady, W. J., Pärnamets, P., Freedman, I. G., Knowles, E. D., \& Van Bavel, J. J. (2020). Partisan differences in physical distancing are linked to health outcomes during the COVID-19 pandemic. Nature human behaviour, 1-12. https://www.nature.com/articles/s41562-020-00977-7

Guess, A. M. (2015). Measure for measure: An experimental test of online political media exposure. Political Analysis, 23(1), 59-75. https://www.cambridge.org/core/journals/political-analysis/article/measure-formeasure-an-experimental-test-of-online-political-mediaexposure/6C3A1C40E789E076F20E6E32C4B6A359

Guess, A., Nagler, J., \& Tucker, J. (2019). Less than you think: Prevalence and predictors of fake news dissemination on Facebook. Science advances, 5(1), eaau4586. https://advances.sciencemag.org/content/5/1/eaau4586

Hess, A. (2014). Why women aren't welcome on the internet, Pacific Standard, 6 January. https://psmag.com/social-justice/women-arent-welcome-internet-72170

Jürgens, P., Stark, B., \& Magin, M. (2020). Two half-truths make a whole? On bias in self-reports and tracking data. Social Science Computer Review, 38(5), 600-615. https://journals.sagepub.com/doi/abs/10.1177/0894439319831643

Kim, S., Lee, J., \& Yoon, D. (2015). Norms in social media: The application of theory of reasoned action and personal norms in predicting interactions with Facebook page like ads. Communication Research Reports, 32, 322-331. https://www.tandfonline.com/doi/abs/10.1080/08824096.2015.1089851?journalC ode $=$ rcrr20

Lucid. (2020). Lucid Theorem Frequently Asked Questions. Retrieved from: https://lucidtheorem.com/faq

Lyons, B., Mérola, V., Reifler, J., \& Stoeckel, F. (2020). How Politics Shape Views Toward Fact-Checking: Evidence from Six European Countries. The International Journal of Press/Politics, 25(3), 469-492. https://journals.sagepub.com/doi/abs/10.1177/1940161220921732?journalCode=h ijb

Malhotra, P. (2020). A Relationship-Centered and Culturally Informed Approach to 
Studying Misinformation on COVID-19. Social Media + Society, 6(3), 2056305120948224.

https://journals.sagepub.com/doi/full/10.1177/2056305120948224

Margolin, D. B., Hannak, A., \& Weber, I. (2018). Political fact-checking on Twitter: When do corrections have an effect? Political Communication, 35, 196-219. https://www.tandfonline.com/doi/abs/10.1080/10584609.2017.1334018?.journalC ode $=$ upcp20

Mitchell, A., Gottfried, J., Stocking, G., Walker, M., \& Fedeli, S. (2019). Many Americans Say Made-Up News Is a Critical Problem That Needs To Be Fixed. Pew Research Center. https://www.journalism.org/2019/06/05/many-americanssay-made-up-news-is-a-critical-problem-that-needs-to-be-fixed/

Rich, T. S., Milden, I., \& Wagner, M. T. (2020). Research note: Does the public support fact-checking social media? It depends who and how you ask. The Harvard Kennedy School Misinformation Review. https://misinforeview.hks.harvard.edu/article/research-note-does-the-publicsupport-fact-checking-social-media-it-depends-who-and-how-you-ask/

Roozenbeek, J., Schneider, C. R., Dryhurst, S., Kerr, J., Freeman, A. L., Recchia, G., ... \& Van Der Linden, S. (2020). Susceptibility to misinformation about COVID-19 around the world. Royal Society open science, 7(10), 201199. https://royalsocietypublishing.org/doi/10.1098/rsos.201199

Schaeffer, K. (2020). Nearly three-in-ten Americans believe COVID-19 was made in a lab. Retrieved from: https://www.pewresearch.org/fact-tank/2020/04/08/nearlythree-in-ten-americans-believe-covid-19-was-made-in-a-lab/

Shin, J., \& Thorson, K. (2017). Partisan selective sharing: The biased diffusion of factchecking messages on social media. Journal of Communication, 67(2), 233-255. https://onlinelibrary.wiley.com/doi/abs/10.1111/jcom.12284

Sudman, S., Bradburn, N.M., \& Schwarz, N. (1996). Thinking About Answers: The Application of Cognitive Processes to Survey Methodology. San Francisco, CA: Jossey-Bass Publishers.

Tandoc Jr, E. C., Lim, D., \& Ling, R. (2020). Diffusion of disinformation: How social media users respond to fake news and why. Journalism, 21, 381-398. https://journals.sagepub.com/doi/abs/10.1177/1464884919868325? journalCode $=\mathrm{j}$ oua 
Thorson, K. (2014). Facing an uncertain reception: Young citizens and political interaction on Facebook. Information, Communication \& Society, 17, 203-216. https://www.tandfonline.com/doi/abs/10.1080/1369118X.2013.862563

Vraga, E. K., \& Bode, L. (2020). Correction as a Solution for Health Misinformation on Social Media. American Journal of Public Health, 110 (S3), S278-S280. https://ajph.aphapublications.org/doi/full/10.2105/AJPH.2020.305916

Vraga, E. K., Tully, M., \& Bode, L. (2020). Empowering users to respond to misinformation about Covid-19. Media and communication (Lisboa), 8(2), 475479. https://www.cogitatiopress.com/mediaandcommunication/article/view/3200

Vraga, E. K., Thorson, K., Kligler-Vilenchik, N., \& Gee, E. (2015). How individual sensitivities to disagreement shape youth political expression on Facebook. Computers in Human Behavior, 45, 281-289. https://www.sciencedirect.com/science/article/abs/pii/S0747563214007419

Walter, N., Brooks, J. J., Saucier, C. J., \& Suresh, S. (2020). Evaluating the impact of attempts to correct health misinformation on social media: A metaanalysis. Health Communication, 1-9. https://www.tandfonline.com/doi/full/10.1080/10410236.2020.1794553

Waterloo, S. F., Baumgartner, S. E., Peter, J., \& Valkenburg, P. M. (2018). Norms of online expressions of emotion: Comparing Facebook, Twitter, Instagram, and WhatsApp. New Media \& Society, 20(5), 1813-1831.

https://journals.sagepub.com/doi/full/10.1177/1461444817707349 